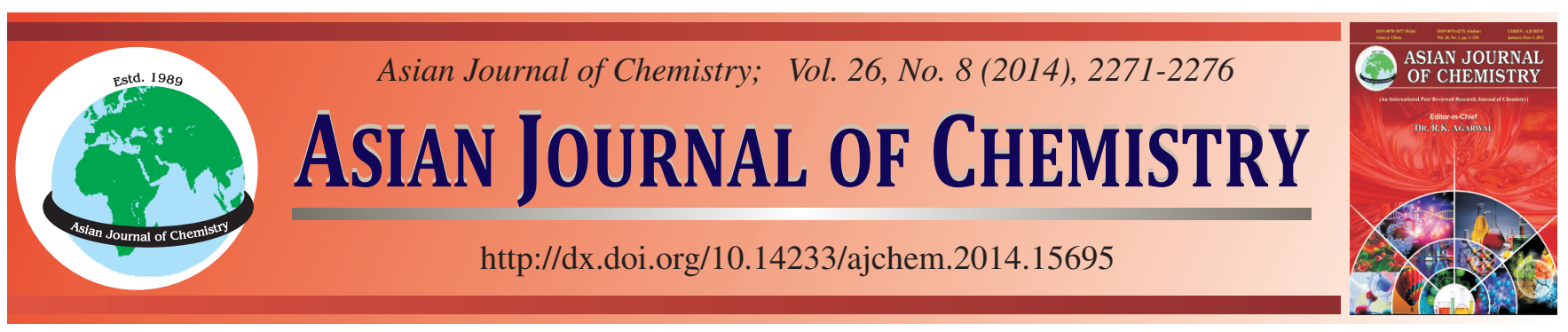

\title{
Effect of Ionic Liquid on Separation and Purification of Tea Polyphenols Using Counter Current Chromatography
}

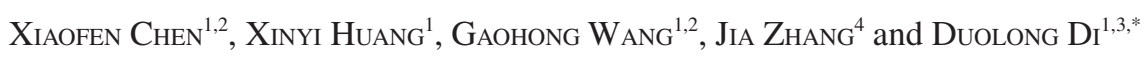

${ }^{1}$ Key Laboratory of Chemistry of Northwestern Plant Resources, Chinese Academy of Sciences \& Key Laboratory for Natural Medicine of Gansu Province, Lanzhou Institute of Chemical Physics, Chinese Academy of Sciences, Lanzhou 730000, P.R. China

${ }^{2}$ Graduate University of Chinese Academy of Sciences, Beijing 100049, P.R. China

${ }^{3}$ Center of Resource Chemical and New Material, Lanzhou Institute of Chemical Physics, Chinese Academy of Sciences, No. 36, Jinshui Road, Qingdao 266100, P.R. China

${ }^{4}$ Department of Pharmacy, Gansu College of Traditional Chinese Medicine, No. 35, Dingxi East Road, Lanzhou 730000, P.R. China

*Corresponding author: Fax: +86 931 8277088; Tel: +86 931 4968248; E-mail: didl@ licp.cas.cn

Received: 26 April 2013;

Accepted: 28 August 2013;

Published online: 15 April 2014;

AJC-15007

In order to research the effect of ionic liquid as additives in two-phase solvent system on the behaviour of counter-current chromatography and develop more efficient methods of preparative separation and purification for natural products, a series of imidazolium-based ionic liquids with anion of $\left[\mathrm{BF}_{4}\right]^{-}$(1-methyl-3-methylimidazolium tetrafluoroborate, 1-ethyl-3-methylimidazolium tetrafluoroborate, 1-propyl3-methylimidazolium tetrafluoroborate, 1-butyl-3-methylimidazolium tetrafluoroborate) and four structurally similar tea polyphenols ((-)-epigallocatechin-3-gallate, (-)-epicatechin, (-)-epicatechin-3-gallate, (-)-gallocatechin gallate) were, respectively chosen as additives and model molecules. The results showed that with the additive of $0.6 \mathrm{~mol} / \mathrm{L}$ [MMIM] $\left[\mathrm{BF}_{4}\right]$ in ethyl acetate-water solvent system, the $\mathrm{K}$ values of (-)-epicatechin-3-gallate could drop from 30.46 to 3.47 . The process of screening solvent systems based on ionic liquids was simpler and more efficiency than traditional ways. Subsequently, IR and NMR spectrum were performed to investigate the interactions between tea polyphenols and ionic liquids. It was considered that the major interaction between ionic liquid and target compounds was electrostatic attraction.

Keywords: Counter current chromatography, Ionic liquids, Tea polyphenols.

\section{INTRODUCTION}

Counter current chromatography (CCC) has been widely used in the field of preparative isolation and purification for variously active constituents in natural products ${ }^{1-3}$. It possessed the advantages of high efficiency, high recovery and easy to scale-up preparation. In counter current chromatography, it was crucial to select the suitable two-phase solvent system, which should provide an ideal range of the coefficients $(\mathrm{K})$ of the target compounds. The traditional procedure of screening suitable two-phase solvent system based on empirical methods, such as solvent system screening ${ }^{4}$, ARIZONA $^{5}$ and GUESSmix ${ }^{6}$ methods. However, it was a time-consuming, labor-intensive, low efficiency and solvent-wasting procedure by using empirical methods above mentioned. It was necessary to develop an efficient approach to improve separation efficiency through faster screening of suitable two-phase solvent system in HScounter current chromatography.

In recent years, ionic liquids have been widely employed in analytical and separation field including gas chromatography ${ }^{7-9}$, high performance liquid chromatography ${ }^{10,11}$ and extraction process $^{12,13}$. Also, there were some attempts to explore ionic liquids as the additives of two-phase solvent system in counter current chromatography separation ${ }^{14,15}$ and the solvent systems based on ionic liquids showed some advantages to separate and purify structure similar compounds compared with traditional solvent systems ${ }^{16}$. In this study, a series of imidazoliumbased ionic liquids with the anion of $\left[\mathrm{BF}_{4}\right]^{-}, 1$-methyl-3-methylimidazolium tetrafluoroborate ([MMIM] $\left.\left[\mathrm{BF}_{4}\right]\right)$, 1-ethyl-3-methylimidazolium tetrafluoroborate ([EMIM] $\left.\left[\mathrm{BF}_{4}\right]\right)$, 1-propyl-3methylimidazolium tetrafluoroborate ([PrMIM] $\left[\mathrm{BF}_{4}\right]$ ), 1butyl-3-methylimidazolium tetrafluoroborate ([BMIM] $\left[\mathrm{BF}_{4}\right]$ ) (Fig. 1) were chosen to investigate the effect of ionic liquids as additives in counter current chromatography separation and the interaction mechanism between ionic liquids and target compounds.

Tea (Camellia sinensis L.) has been widely consumed around the world as one of the most popular beverages. Numerous epidemiological and pharmacological studies showed that green tea extract possessed desirable biological 


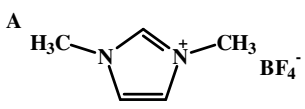

C<smiles></smiles>

B

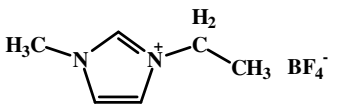

$\mathrm{D}_{3} \mathrm{C}_{-}$

Fig. 1. Structures of ionic liquids employed in present study. A. [MMIM] $\left[\mathrm{BF}_{4}\right]$;



and physiological effects, such as antioxidation ${ }^{17}$, anticancer ${ }^{18,19}$, antiinflammation $^{20}$, antiatherosclerosis and cardioprotection ${ }^{21}$, neuroprotectiveactivity ${ }^{22}$. The majority of the biological activities of tea was ascribed to the tea polyphenol compounds, including (-)-epigallocatechin-3-gallate (EGCG), (-)-epicatechin (EC), (-)-epicatechin-3-gallate (ECG), (-)-gallocatechin gallate $(\mathrm{GCG})^{23},(-)$-epigallocatechin (EGC), etc. Above tea polyphenol compounds possessed similar structures (Fig. 2) and it was difficult to screening a suitable solvent system quickly for separating them in counter current chromatography. In this study, EGCG, EC, GCG and ECG (Fig. 2) were chosen as model molecules to research effect of ionic liquid as the additives in two-phase solvent system on countercurrent chromatography behaviour. Furthermore, the possible interaction mechanism between ionic liquids and target compounds was studied by molecular simulation, IR and NMR spectrum.


Fig. 2. Structures of tea polyphenols. A. EGCG; B. EC; C. GCG; D. ECG

\section{EXPERIMENTAL}

Ethyl acetate used for counter current chromatography separation was of analytical grade and purchased from the Yantai Shuangshuang Chemicals Co., Ltd. (Shandong, China). Deionized water was used throughout the experiment. Methanol used for HPLC analysis was of chromatographic grade and purchased from the Yuwang Chemical Reagent Co. Ltd. (Shandong, China). Green tea leaves (production area: Longnan) were obtained from a local market in Longnan City (Gansu Province, China). The reference compounds of EGCG, EC, GCG and ECG were purchased from Chengdu Purifa Technology Development Co., Inc. (Sichuan, China) and the purity were over $99.0 \%$.

The counter current chromatography instrument was the CCC DE Spectrum (Dynamic Extractions Co. Ltd, Slough, UK) equipped with two bobbins in the present study. Each bobbin of the apparatus fits one analytical column and one preparative column made by polytetrafluroethylene (PTFE). In this study, the analytical scale was employed. The column volume of each analytical column is $14 \mathrm{~mL}$ of $0.8 \mathrm{~mm}$ ID. The $\beta$-value is defined as $\beta=r / R$, where $r$ is the coiled tubing radius and $\mathrm{R}$ is the revolution radius or the distance between the coil axis and holder frame central axis. In this case, $\beta$ varied from 0.64 at the internal terminal to 0.81 at the external terminal for the analytical columns. The maximum rotational speed of the Spectrum counter current chromatography instrument is limited to $1600 \mathrm{rpm}$. A rotation speed of $1500 \mathrm{rpm}$ was used in this study giving a high " $\mathrm{g}$ " value of $225 \mathrm{~g}$. The counter current chromatography separation setup consisted of two preparative pumps H\&E P3000A and a spectrophotometer H\&E UV3000 (H\&E Co. Ltd., Beijing, China) with a preparative cell operating. The separation temperature was controlled by a DLSB$10 / 40{ }^{\circ} \mathrm{C}$ constant temperature regulator (Yarong Instruments Co. Ltd., Zhengzhou, China). A CBS-A automatic fraction collector (Shanghai Huxi Analysis Instrument Factory Co. Ltd., Shanghai, China) was used to collect each fraction. The HPLC analysis was performed in an Agilent 1200 Series (Agilent Technologies, USA) LC system, which was equipped with a G1322A vacuum degasser, a G1311A quaternary pump, a G1315D diode array detector (DAD) and a G1328B manual injection valve with a $20 \mu \mathrm{L}$ loop. The system was controlled by Agilent Chemstation software (version A.10.02) (Agilent Technologies, USA). Infrared spectra of the ionic liquid and ionic liquid mixed with target compounds were obtained from a Nexus-670 FT-IR spectrometer (Nicolet, Madison, WI, USA) with a pellet of powdered potassium bromide and adsorbent in the range of 500-4000 $\mathrm{cm}^{-1}$. NMR spectra were recorded on a Varian Inova-400 FT-NMR spectrometer (Palo Alto, CA, USA) with TMS as an internal standard, $\delta$ in ppm, $J$ in $\mathrm{Hz}$.

Preparation of sample solution: Standard stock solutions of EGCG, EC, GCG and ECG at concentrations of approximately $2 \mathrm{mg} \mathrm{mL}^{-1}$ were, respectively prepared and then stored at $-4{ }^{\circ} \mathrm{C}$. The injection sample solution was prepared by mixing $250 \mu \mathrm{L}$ of each stock solution together before counter current chromatography separation. The sample for IR and NMR elucidation was, respectively prepared by dissolving $7 \mathrm{mmol}$ EGCG, EC, GCG and ECG in $30 \mu \mathrm{L}$ [MMIM] $\left[\mathrm{BF}_{4}\right]$ and stored at $-4{ }^{\circ} \mathrm{C}$.

Investigation of $\mathrm{K}$ values based on ionic liquids as the additives of two-phase solvent systems: In the present study, the solvent systems were prepared by dissolving a certain amount of ionic liquids in the basic solvent system of ethyl acetate-water. The partition coefficient was defined as $\mathrm{K}=\mathrm{A}_{\text {upper }} / \mathrm{A}_{\text {lower }}$, where $\mathrm{A}_{\text {upper }}$ and $\mathrm{A}_{\text {lower }}$ were peak areas of target compounds in the upper and lower phases, respectively. The partition coefficients $(\mathrm{K})$ values of the target compounds in different solvent systems were measured by HPLC as follows: Suitable amount of reference compounds were added into a series of test tubes filled with different pre-equilibrated twophase solvent systems. Then, the test tubes were shaken vigorously to mix the sample with the solvents thoroughly following by standing to reach the dynamic equilibrium. Finally, the upper and lower phases were, respectively analyzed by HPLC for measurement of the partition coefficient (K).

Counter current chromatography separation procedure: Analytical counter current chromatography patterns were carried out in this study. The separation procedure was 
performed as follows: the upper phase of solvent system (ethyl acetate-water-ionic liquids) was pumped into the analytical column as stationary phase. Then, the lower phase of solvent system as mobile phase was pumped into the system at a constant flow rate of $1 \mathrm{~mL} / \mathrm{min}$ in the head to tail elution mode for a reversed-phase separation. The centrifuge rotation speed was set at $1500 \mathrm{rpm}$ at $30^{\circ} \mathrm{C}$. The effluents were collected using a measuring cylinder, it meant hydrodynamic equilibrium was established when the lower phase was observed outflowing. Then, $1 \mathrm{~mL}$ of sample solution was injected into the column. The effluent out the end of the column was monitored with an UV detector at $280 \mathrm{~nm}$ and all fractions were collected and stored for subsequent HPLC analysis.

HPLC analysis and identication of counter current chromatography peak fractions: The standard solutions and counter current chromatography fractions were analyzed by HPLC at the wavelength of $280 \mathrm{~nm}$ using a photodiode array detector. The analysis was accomplished with a Sinochrom ODS-BP column $(250 \mathrm{~mm} \times 4.6 \mathrm{~mm} \mathrm{id}, 5 \mu \mathrm{m})$ at $30{ }^{\circ} \mathrm{C}$. The separation was carried out with a binary mobile phase consisting of $1 \%$ acetic acid buffer solution (solvent $\mathrm{A}$ ) and methanol (solvent B). The gradient elution program at $1 \mathrm{~mL} / \mathrm{min}$ was set as follows: a linear gradient of solvent B from 15-30 \% (0-5 min), $30 \%$ of solvent B (5-15 min), 30-38\% of solvent B (15-25 min), $38 \%$ of solvent B (25-35 min).

\section{RESULTS AND DISCUSSION}

Effect of ionic liquids as the additives of two-phase solvent system on $\mathbf{K}$ values: Reliable new hydrodynamic instruments were developed by Dynamic Extraction ${ }^{24}$. Compared to preparative liquid chromatography, counter current chromatography has the obvious advantages of a higher sample loading capacity without any irreversible adsorption associated to a flexible operation mode working with a wide range of solvent systems. In counter current chromatography, the selection of a suitable two-phase solvent system was the most important problem for efficient separation. It was crucial for efficient separation and the satisfactory $\mathrm{K}$ value was usually considered in the range of 0.5-2.0. Commonly, the procedure of screening solvent system was as follows: by adjusting the ratio of various solvents, a ternary or multi-component solvent system was obtained. Then, the $\mathrm{K}$ values of target compounds were measured by dissolving samples in equal volumns of upper and lower phase. The procedure was repeated until appropriate $\mathrm{K}$ value was obtained. However, it was a time-consuming, labor-intensive, low efficiency and solvent-wasting procedure. In this study, considering the moderate polarity of the EGCG, EC, GCG and ECG, the original solvent system of ethyl acetate-water was chosen. Ascribe to the four compounds dissolved much more in the upper phase of ethyl acetate-water solvent system, it was found that the $\mathrm{K}$ values were too large to get achieve separation in counter current chromatography procedure (Fig. 3).

In order to establish a shortcut approach for screening ideal $\mathrm{K}$ values, the effect of ionic liquids as the additives of two-phase solvent system on $\mathrm{K}$ values was studied. Hence, the object of this work was to improve the solubility of target compounds in water to obtain suitable $\mathrm{K}$ values. Considering

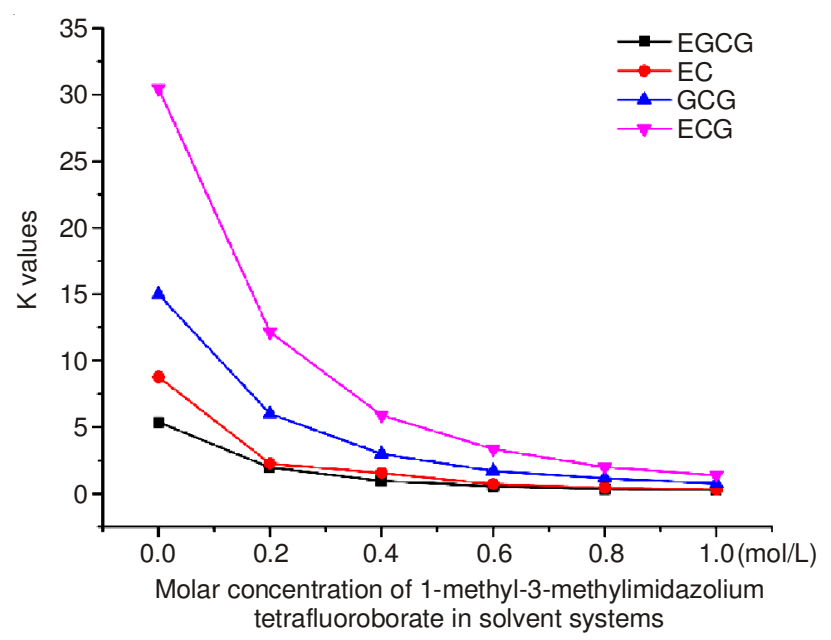

Fig. 3. Effect of the concentration of $[\mathrm{MMIM}]\left[\mathrm{BF}_{4}\right]$ on $\mathrm{K}$ values to the four target compounds in ethyl acetate-water $(5: 5, \mathrm{v} / \mathrm{v})$

ionic liquids have multi-reactions such as $\pi-\pi$, ionic/chargecharge and hydrogen bonding with compounds as well as excellent dissolving capability for plenty of organic and inorganic compounds based on previous researches ${ }^{25}$. Hydrophilic imidazole ionic liquids consisting of $\left[\mathrm{BF}_{4}\right]^{-}, \mathrm{Br}^{-}$and $\mathrm{Cl}^{-}$ inorganic anions such as [EMIM][Cl], [PrMIM][Cl], [EMIM] [Br], [PrMIM] $\mathrm{Br}],[\mathrm{EMIM}]\left[\mathrm{BF}_{4}\right]$ and $[\mathrm{PrMIM}]\left[\mathrm{BF}_{4}\right]$ were added in the solvent systems to adjust the $\mathrm{K}$ values. However, it was found that the ionic liquids containing $\mathrm{Br}^{-}$ and $\mathrm{Cl}^{-}$could react with the four model compounds (Fig. 4).
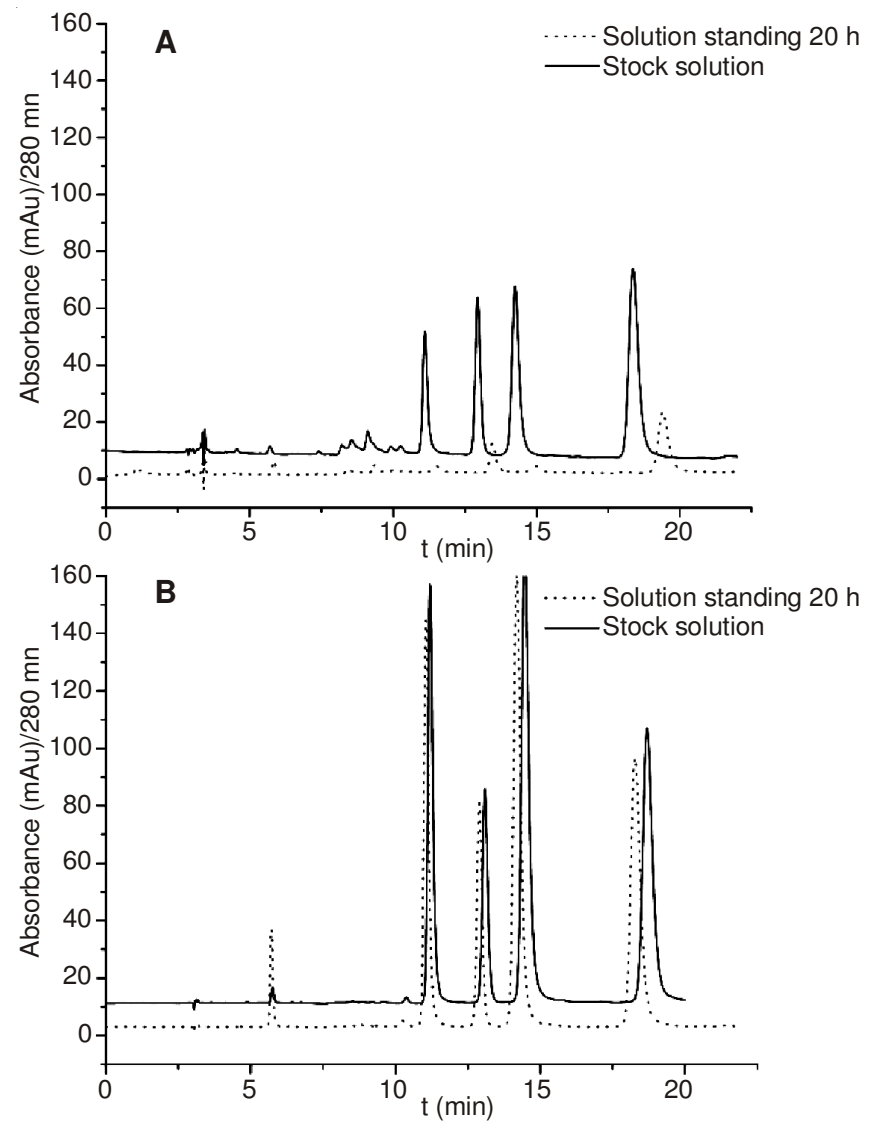

Fig. 4. HPCL chromatogram of sample solutions and solution stand for 20h. A. sample solution added with [PrMIM][Cl]; B sample solution added without any ionic liquids 
Therefore, ionic liquids composed of $\left[\mathrm{BF}_{4}\right]^{-}$and cations containing different length of the carbon chain, including $[\mathrm{MMIM}]\left[\mathrm{BF}_{4}\right],[\mathrm{EMIM}]\left[\mathrm{BF}_{4}\right],[\mathrm{PrMIM}]\left[\mathrm{BF}_{4}\right]$ and $[\mathrm{BMIM}]\left[\mathrm{BF}_{4}\right]$, were chosen as solvent additives in ethyl acetate-water solvent system. To simplify the experimental process, the [MMIM] $\left[\mathrm{BF}_{4}\right]$ was chose as representative to test $\mathrm{K}$ values of EGCG, EC, GCG and ECG in ethyl-water-[MMIM] $\left[\mathrm{BF}_{4}\right]$ solvent system. As can be seen in Fig. 3, the $\mathrm{K}$ values of all compounds possessed the similar trend of decreasing with the increasing molar concentration of $[\mathrm{MMIM}]\left[\mathrm{BF}_{4}\right]$. It was also shown that addition of $[\mathrm{MMIM}]\left[\mathrm{BF}_{4}\right]$ could signicantly improve the partition coefficient ascribed to some interaction between ionic liquids and the four target compounds.

Effect of ionic liquids as additives on the counter current chromatography separation: The results indicated that without any ionic liquids added in the solvent system, the $\mathrm{K}$ values of EGCG, EC, GCG and ECG were too large to carry out counter current chromatography operation using the solvent system ethyl acetate-water. With the increase of concentration of ionic liquids, the $\mathrm{K}$ values of the four compounds decreased obviously. Finally, considering the relatively suitable K values of all compounds, solvent system of ethyl acetate-water$[\mathrm{MMIM}]\left[\mathrm{BF}_{4}\right](5: 5: 0.6, \mathrm{v} / \mathrm{v} / \mathrm{M})$ was selected as the two-phase solvent system in this experiment. For the purpose of this work was not to get purified substances, the specific investigation of separation conditions of counter current chromatography was not necessary. Therefore, the revolution speed of the separation column, the flow rate of the mobile phase and the amount of injected sample were set empirically. The revolution speed was $1500 \mathrm{rpm}$, the flow rate was $1 \mathrm{~mL} / \mathrm{min}$ at $30{ }^{\circ} \mathrm{C}$ and the injected sample solution was $1 \mathrm{~mL}$. Also, the solvent systems added [EMIM] $\left[\mathrm{BF}_{4}\right],[\operatorname{PrMIM}]\left[\mathrm{BF}_{4}\right]$ and $[\mathrm{BMIM}]\left[\mathrm{BF}_{4}\right]$ were employed to perform counter current chromatography separation. The molar concentrations of all ionic liquids were kept at the same level at $0.6 \mathrm{~mol} / \mathrm{L}$ and the separation conditions of flow rate, revolution speed and sample injection were all the same. The counter current chromatography chromatograms were shown in Fig. 5. It could be observed that as the additives' side chain on imidazolium ring became longer, the retention time of EGCG, EC, GCG and ECG became shorter (Fig. 5).

It meant that longer alkyl chain on imidazolium cation have greater effect on the partition than that of shorter alkyl chain. The counter current chromatography results also indicated that the ionic liquids with longer side chain on cation could have stronger interaction with separated compounds. Lassègues et al. ${ }^{26,27}$ reported that the interaction between cation and anion in ionic liquids was electrostatic attraction which made them bonded together tightly. In reference ${ }^{28}$, it was demonstrated that in ionic liquids, the charged anions and headgroups of the cations distribute homogeneously because of the strong electrostatic interactions, while the neutral tail groups of the cations tend to aggregate due to the collective short-range interaction and it could be deduced that interaction between cation with shorter side chain and anion was stronger. Also, in previous studies, it was reported that the interaction between 1-alkyl-3-methylimidazolium cation with shorter alkyl and the anion of $\left[\mathrm{BF}_{4}\right]^{-}$were stronger ${ }^{29}$. Computer simulation was done to analyze the charge distribution of ionic liquids to investigate the side chain effect on counter current chromatography separation. The method was performed as follows:


Fig. 5. Analytical counter current chromatography chromatograms. Solvent systems: A: ethyl acetate-water-[MMIM][BF $]$ (5:5:0.6, v/v/M); B: ethyl acetatewater-[EMIM] $\left[\mathrm{BF}_{4}\right]$ (5:5:0.6, v/v/M); C: ethyl acetate-water-[PrMIM][BF 4 (5:5:0.6, v/v/M); D: ethyl acetate-water-[BMIM][BF $]$ (5:5:0.6, v/v/M). Other conditions: The lower phase as mobile phase and the upper phase as stationary phase; flow rate: $1 \mathrm{~mL} / \mathrm{min}$; revolution speed: $1500 \mathrm{rpm}$; detection wavelength: $280 \mathrm{~nm}$; separation temperature: $30^{\circ} \mathrm{C}$; sample injection: $1 \mathrm{~mL}$ sample solution 
the charge distributions for the imidazolium cation were obtained by optimizing with Gaussian 09 package $^{30}$ at B3LYP/ 6-31G(d) computational level and the mulliken charges were calculated at the same computational level. Simulations with the B3LYP model show that, with shorter side-chain length, the charge distributions were closer than that of cation with longer chain (Fig. 6).
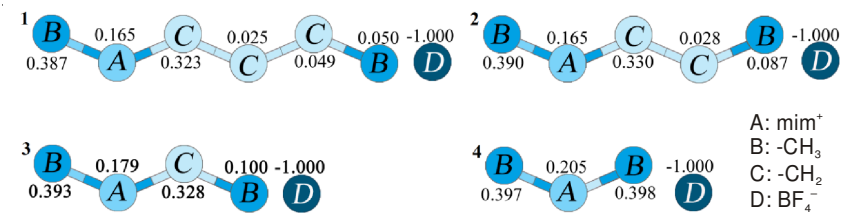

Fig. 6. Illustration of charge distribution of $[\mathrm{MMIM}]\left[\mathrm{BF}_{4}\right]$ (1),

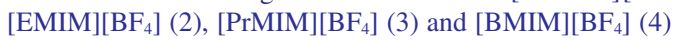

Therefore, it was probably that the smaller cationic radius resulted in stronger electrostatic interaction between shorter side chain cation and $\mathrm{BF}_{4}^{-}$, which weakened the intermolecular forces between ionic liquid and other compounds. So, the major interaction of ionic liquids to the four compounds was electrostatic force rather than hydrogen bonding. It could be proved by following work of IR and NMR spectra measurement.

Mechanism study of ionic liquids interact with target compounds by IR and NMR spectrum: IR spectra especially Fourier transform infrared spectrum (FTIR) and NMR were the conventional means to investigate the existing of hydrogenbonding $^{31-33}$. In NMR, the formation of hydrogen bond could cause NMR signal shifting to a lower field because of the deshielding effect resulted from electrostatic attraction between proton donor and acceptor. In IR spectra, the absorption band tends to become broader and shift as the formation of hydrogen bond. In this study, [MMIM] $\left[\mathrm{BF}_{4}\right]$ was chosen as representative to carry out IR and NMR measurement. There was some difference between the IR spectra of pure ionic liquid and ionic liquid mixed with EGCG, EC, GCG and ECG (Fig. 7).
The assignment of the peaks was shown in Table-1. It was found that the adsorbance of IR spectra of ionic liquid wholly decreased greatly after mixing target compounds, but without any hydrogen bond shift. The reason why this phenomenon appeared was probably that there were some electron acceptor and donor around the ionic liquid's cation and anion, which decreased vibration intensity of the functional groups. Correspondingly, the infrared intensity weakened. Also, the ${ }^{1} \mathrm{H}$ NMR spectrum was measured in this research. The results showed there had not been any change in chemical shift of all hydrogen atoms for ionic liquid and ionic liquid mixed with the four compounds. Take into account of the counter current chromatography behaviour after adding ionic liquids in solvent system ethyl acetate-water, IR and ${ }^{1} \mathrm{H}$ NMR spectrum of pure ionic liquid and ionic liquid mixed with the four polyphenols, it was considered that the electrostatic attraction played an important role in the interaction between ionic liquids and target compounds.

\begin{tabular}{cl}
\multicolumn{2}{c}{ TABLE-1 } \\
\hline \multicolumn{2}{c}{ ASSIGNMENT OF IR BANDS OF [MMIm] $\left[\mathrm{BF}_{4}\right]$} \\
\hline$\lambda_{\max }\left(\mathrm{cm}^{-1}\right)$ & \multicolumn{1}{c}{ Assigment of IR bands } \\
\hline $3131.881,3170.451$ & $\begin{array}{l}\text { Stretching vibration of C-H bond on } \\
\text { imidazole ring }\end{array}$ \\
$2859.963,2969.887$ & $\begin{array}{l}\text { Stretching vibration of C-H bond of methyl } \\
\text { substituent on imidazole ring } \\
\text { skeletal stretching of imidazole ring } \\
1577.512,1616.082 \\
1178.313\end{array}$ \\
$\begin{array}{l}\text { In-plane deformation vibration of C-H bond } \\
\text { on imidazole ring } \\
\text { Stretching vibration of B-F bond }\end{array}$ \\
\hline
\end{tabular}

Identification and HPLC analysis of counter current chromatography fractions: All fractions were collected and analyzed by HPLC. The identification of each peak fraction of counter current chromatography was performed by HPLC detection and UV-visible spectrum. According to the comparison of retention time on HPLC chromatogram and the spectral adsorption peak of UV-visible spectrum, peak Iwas identied as EGCG, peakII was EC, peak III was GCG and peak IV was

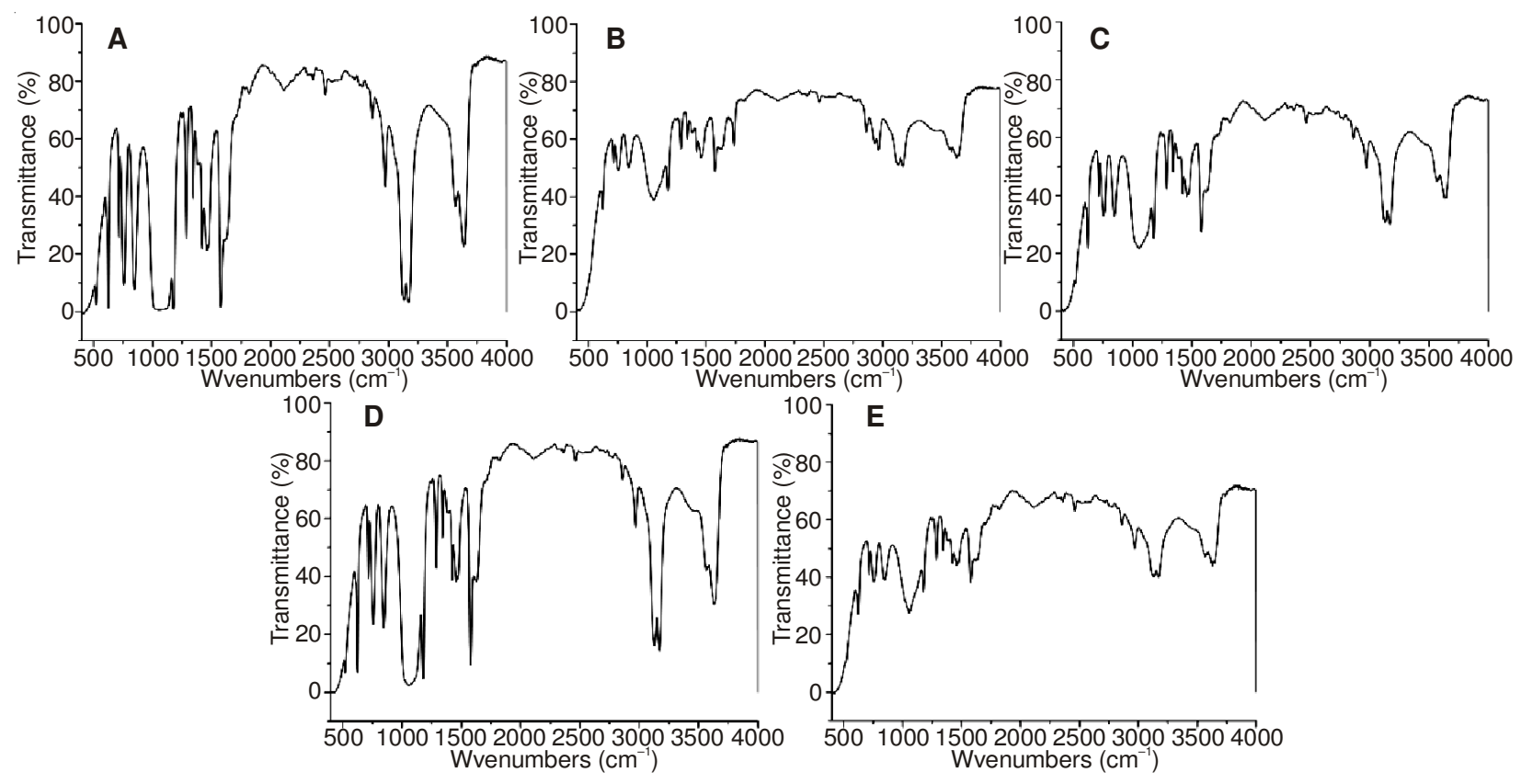

Fig. 7. IR spectra of $[\mathrm{MMIM}]\left[\mathrm{BF}_{4}\right](\mathrm{A})$ and $[\mathrm{MMIM}]\left[\mathrm{BF}_{4}\right]$ with EGCG (B), EC (C), GCG (D) and ECG (E) 
identied as ECG. The HPLC chromatograms of sample solutions and purified compounds were shown in Fig. 8.

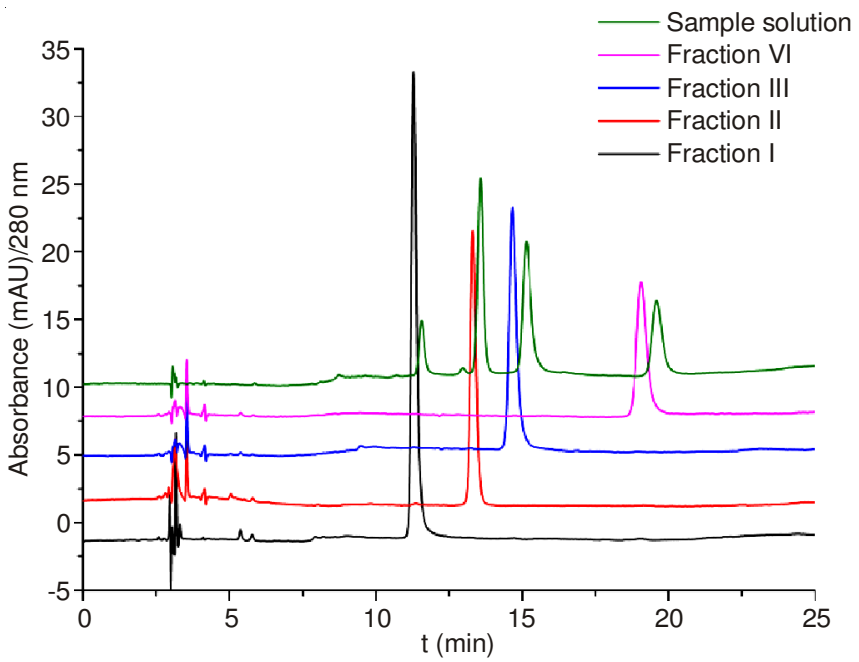

Fig. 8. HPLC chromatograms of sample solution and HP-counter current chromatography fractions

\section{Conclusion}

In this study, to simplify the solvent system screening in counter current chromatography and investigate the interaction of target compounds with ionic liquids, series of imidazoliumbased ionic liquids with the anion of $\mathrm{BF}_{4}^{-}$were studied. And the target compounds were chosen as the four structurally similar tea polyphenols of (-)-epigallocatechin-3-gallate (EGCG), (-)-epicatechin (EC), (-)-gallocatechin gallate (GCG), (-)-epicatechin-3-gallate (ECG). The effect of ionic liquids (ionic liquids) as additives in two-phase solvent system of ethyl acetate-water in counter current chromatography was investigated. The study indicated that the solvent system screening was simpler through modifying the concentrations of ionic liquids rather than fine adjusting the component proportion of different solvents. The ionic liquids showed strong separation ability in counter current chromatography application. It was considered that the major interaction between ionic liquid and target compounds was electrostatic attraction by computer simulation, IR spectroscopic and NMR analysis. However, it was found that the four compounds of EGCG, EC, GCG and ECG could react with ionic liquids containing anion of $\mathrm{Br}^{-}$ and $\mathrm{Cl}^{-}$and the mechanism need further study, which reminded scientists who would use ionic liquids as extraction medium should take into account of possible chemical reaction.

\section{ACKNOWLEDGEMENTS}

This research was supported by the Natural Sciences Foundation of China (NSFC No. 21175142), the "Hundred Talents Program" of the Chinese Academy of Sciences (CAS) and West Light Foundation of The Chinese Academy of Science and Open Fund of Key Laboratory of Chemistry of Northwestern Plant Resources of The Chinese Academy of Science (No. CNPR-2011kfkt-02).

\section{REFERENCES}

1. M. Schröder and W. Vetter, J. Chromatogr. A, 1237, 96 (2012).

2. E.L. Regalado, S. Tolle, J.A. Pino, P. Winterhalter, R. Menendez, A.R. Morales and J.L. Rodríguez, J. Chromatogr. A, 1218, 7358 (2011).

3. G.L. Song and Q.Z. Du, J. Chromatogr. A, 1217, 5930 (2010).

4. Y. Ito, Countercurrent Chromatography, Elsevier Science Publishers B.V., Amsterdam, p. A69 (1992).

5. A.P. Foucault and L. Chevolot, J. Chromatogr. A, 808, 3 (1998).

6. J.B. Friesen and G.F. Pauli, J. Chromatogr. A, 1216, 4225 (2009).

7. C.D. Tran, I. Mejac, J. Rebek and R.J. Hooley, Anal. Chem., 81, 1244 (2009).

8. J. González-Álvarez, D. Blanco-Gomis, P. Arias-Abrodo, D. DíazLlorente, N. Ríos-Lombardía, E. Busto, V. Gotor-Fernández and M.D. Gutiérrez-Álvarez, Anal. Chim. Acta, 721, 173 (2012).

9. X.J. Sun, Y.L. Zhu, P. Wang, J. Li, C.Y. Wu and J. Xing, J. Chromatogr. A, 1218, 833 (2011).

10. V. Pino and A.M. Afonso, Anal. Chim. Acta, 714, 20 (2012).

11. A.V. Herrera-Herrera, J. Hernández-Borges and M.Á. RodríguezDelgado, J. Chromatogr. A, 1216, 7281 (2009).

12. C.H. Ma, T.T. Liu, L. Yang, Y.G. Zu, X.Q. Chen, L. Zhang, Y. Zhang and C.J. Zhao, J. Chromatogr. A, 1218, 8573 (2011).

13. V. Vièkaèkaitë and A. Padarauskas, Cent. Eur. J. Chem., 10, 652 (2012).

14. A. Berthod and S. Carda-Broch, Anal. Bioanal. Chem., 380, 168 (2004).

15. A. Berthod and S. Carda-Broch, J. Liq. Chromatogr. Rel. Technol., 26, 1493 (2003).

16. R.M. Liu, L.L. Xu, A.F. Li and A.L. Sun, J. Sep. Sci., 33, 1058 (2010).

17. R. Farhoosh, G.A. Golmovahhed and M.H.H. Khodaparast, Food Chem., 100, 231 (2007).

18. I. Naasani, F. Oh-Hashi, T. Oh-Hara, W.Y. Feng, J. Johnston, K. Chan and T. Tsuruo, Cancer Res., 63, 824 (2003).

19. B. Bannerman, L. Xu, M. Jones, C. Tsu, J. Yu, P. Hales, J. Monbaliu, P. Fleming, L. Dick, M. Manfredi, C. Claiborne, J. Bolen, E. Kupperman and A. Berger, Cancer Chemother. Pharmacol., 68, 1145 (2011).

20. K. Kawai, N.H. Tsuno, J. Kitayama, Y. Okaji, K. Yazawa, M. Asakage, S. Sasaki, T. Watanabe, K. Takahashi and H. Nagawa, J. Allergy Clin. Immunol., 115, 186 (2005).

21. H.M. Lo, C.F. Hung, Y.Y. Huang and W.B. Wu, J. Biomed. Sci., 14, 637 (2007)

22. L.D. Mercer, B.L. Kelly, M.K. Horne and P.M. Beart, Biochem. Pharmacol., 69, 339 (2005).

23. D. Komes, D. Hor•iæ, A. Belšèak, K.K. Ganiæ and I. Vuliæ, Food Res. Int., 43, 167 (2010).

24. H. Guzlek, P.L. Wood and L. Janaway, J. Chromatogr. A, 1216, 4181 (2009).

25. E.S. Sashina, N.P. Novoselov, O.G. Kuz'mina and S.V. Troshenkova, Fibre Chem., 40, 270 (2008).

26. J.C. Lassègues, J. Grondin, D. Cavagnat and P. Johansson, J. Phys. Chem. A, 113, 6419 (2009).

27. J.C. Lassègues, J. Grondin, D. Cavagnat and P. Johansson, J. Phys. Chem. A, 114, 687 (2010).

28. Y.T. Wang and G.A. Voth, J. Am. Chem. Soc., 127, 12192 (2005).

29. N.E. Heimer, R.E. Del Sesto, Z.Z. Meng, J.S. Wilkes and W.R. Carper, J. Mol. Liq., 124, 84 (2006).

30. M.J. Frisch, G.W. Trucks, H.B. Schlegel, G.E. Scuseria, M.A. Robb, J.R. Cheeseman, G. Scalmani, V. Barone, B. Mennucci, G.A. Petersson, H. Nakatsuji, M. Caricato, X. Li, H.P. Hratchian, A.F. Izmaylov, J. Bloino, G. Zheng, J.L. Sonnenberg, M. Hada, M. Ehara, K. Toyota, R. Fukuda, J. Hasegawa, M. Ishida, T. Nakajima, Y. Honda, O. Kitao, H. Nakai, T. Vreven, J.A. Montgomery Jr., J.E. Peralta, F. Ogliaro, M. Bearpark, J.J. Heyd, E. Brothers, K.N. Kudin, V.N. Staroverov, R. Kobayashi, J. Normand, K. Raghavachari, A. Rendell, J.C. Burant, S.S. Iyengar, J. Tomasi, M. Cossi, N. Rega, J.M. Millam, M. Klene, J.E. Knox, J.B. Cross, V. Bakken, C. Adamo, J. Jaramillo, R. Gomperts, R.E. Stratmann, O. Yazyev, A.J. Austin, R. Cammi, C. Pomelli, J.W. Ochterski, R.L. Martin, K. Morokuma, V.G. Zakrzewski, G.A. Voth, P. Salvador, J.J. Dannenberg, S. Dapprich, A.D. Daniels, O. Farkas, J.B. Foresman, J.V. Ortiz, J. Cioslowski and D.J. Fox, Gaussian, Inc., Wallingford CT (2009).

31. C.P. Lawrence and J.L. Skinner, Chem. Phys. Lett., 369, 472 (2003).

32. L. Dai and L. Ying, Macromol. Mater. Eng., 287, 509 (2002).

33. R. Lungwitz and S. Spange, Chem. Phys. Chem., 13, 1910 (2012). 